\title{
Avaliação da influência do substrato de concreto na resistência de aderência à tração de diferentes tipos de chapisco
}

\section{The influence of concrete substrate in adhesive strength of different types of slurry mortar}

Felipe Allebrand Becker ${ }^{1}$, Jairo José de Oliveira Andrade ${ }^{2}$

\footnotetext{
${ }^{1}$ Curso de Engenharia Civil - Faculdade de Engenharia/PUCRS - Av. Ipiranga, 6681, Prédio 30, Parternon, Porto Alegre, RS

e-mail: lipebecker@hotmail.com

${ }^{2}$ Programa de Pós-Graduação em Engenharia e Tecnologia de Materiais - PGETEMA/PUCRS - Av. Ipiranga, 6681, Prédio 30, Parternon, Porto Alegre, RS

e-mail: jairo.andrade@pucrs.br
}

\section{RESUMO}

O revestimento de argamassa já é utilizado há muitos anos e continua sendo muito empregado ainda nos dias de hoje com o surgimento de novas tendências. Apesar disso, tal subsistema não acompanhou a evolução de outras tecnologias, como o concreto estrutural. Está cada vez mais comum a ocorrência de manifestações patológicas em revestimentos argamassados quando executados sobre estrutura de concreto. Segundo estudos, a ocorrência destas manifestações, especialmente quando aplicado em substratos de concreto, está ligada ao aumento da resistência e da diminuição da porosidade do mesmo. Nesse contexto, este artigo tem como objetivo verificar a perda de aderência de chapiscos com o aumento da resistência do concreto e definir o melhor tipo de chapisco para utilizar sobre este tipo de substrato. Foram moldadas placas de concreto, com variação da resistência característica $\left(f_{\mathrm{ck}}\right)$ de $17,75 \mathrm{MPa}, 29,89 \mathrm{MPa}$ e $35,15 \mathrm{MPa}$. As placas foram chapiscadas com chapisco convencional, rolado e desempenado. Os resultados dos ensaios de aderência comprovaram que o aumento da resistência do concreto reduz a resistência de aderência do revestimento. Os ensaios também mostraram que os chapiscos industrializados se comportam melhor, quando comparado ao convencional, para revestimento de estruturas de concreto.

Palavras-chave: Chapisco, aderência, concreto.

\section{ABSTRACT}

The mortar coating is already used for many years and remains very still employed in construction. Nevertheless, this subsystem did not follow the evolution of other technologies, such as structural concrete. It is increasingly common occurrence of damages in mortars, mainly when used over a concrete structure. In this context, this article has as objective verifies the adhesion of three slurry mortar types when applied in concretes with different compressive strength. Concrete substrates were produced with compressive strength of 17.75 $\mathrm{MPa}, 29.89 \mathrm{MPa}$ and $35.15 \mathrm{MPa}$, where the adhesion tests were performed. The results showed that the increase of concrete strength reduces the adhesive strength, due to the minimization of porosity. Besides, the commercial mortars have better adhesive strength than the manual slurry mortars.

Keywords: Slurry mortar, adhesive strength, concrete.

\section{INTRODUÇÃO}

De acordo com CARASEK [1], o revestimento de argamassa de cimento é uma das técnicas mais antigas empregadas para revestir paredes, tetos e fachadas de edificações. Ainda nos dias de hoje, com o surgimento de diversas novas técnicas e novos métodos de construção para fechamentos e vedações, como divisórias de gesso e fechamentos externos em painéis pré-moldados, a utilização de argamassa não perde a sua importância e continua sendo muito utilizada em obras de construção civil. 
Apesar de já ser muito difundido e amplamente estudado, o revestimento de argamassa ainda apresenta diversas manifestações patológicas, sendo mais frequentes as fissurações e os descolamentos por falta de aderência, principalmente quando executados sobre substratos de concreto. CARASEK et al. [2] verificaram, em estudo realizado em 9 obras em Brasília-DF, que os problemas de aderência ocorreram essencialmente em revestimentos executados sobre as estruturas de concreto, não havendo nenhuma ocorrência sobre as alvenarias. Estas manifestações patológicas podem ser identificadas pela própria fissuração, acompanhada da presença de um som cavo e em algumas ocasiões o desplacamento do revestimento. GASPERIN [3] destacou em seu trabalho que as ocorrências de defeitos em revestimentos nas estruturas de concreto aumentaram, comparado a cerca de 20 anos atrás, pois a predominância na época era de casas térreas e edifícios com poucos pavimentos e pequenos vãos, aliados a maiores prazos de execução. $\mathrm{O}$ autor salientou que difere muito dos tempos atuais, em que os edifícios tendem a ser cada vez mais altos e com vãos maiores, tendo de ser executados em prazos cada vez mais enxutos. Para a ocorrência desta mudança, as estruturas de concreto tiveram de sofrer uma evolução. Um dos fatores que mudaram foi a resistência do concreto, onde era usual a utilização de resistências na ordem de $15 \mathrm{MPa}$ e $18 \mathrm{MPa}$ antigamente para $30 \mathrm{MPa}$ e $35 \mathrm{MPa}$ usuais atualmente (MEHTA e MONTEIRO [4], AÏTICIN [5]).

RUDUIT [6] realizou uma análise criteriosa de resultados de ensaios de resistência de aderência no Rio Grande do Sul, localizados externamente (1158 dados) e internamente (1097 dados), concluindo que os substratos de concreto apresentaram menores valores de aderência se comparados aos substratos de alvenaria (37,5\% menores). Além disso, o substrato de concreto apresentou um valor médio de resistência inferior ao mínimo especificado pela normalização brasileira.

De acordo com PRETTO [7], cada vez mais, com o desenvolvimento e a utilização de concretos de alto desempenho nas estruturas de edifícios, a ocorrência de falta de aderência entre substrato e revestimento é mais frequente. Assim, estas manifestações patológicas tendem a serem mais recorrentes devido à baixa absorção e baixa permeabilidade destes concretos. Vários pesquisadores já realizaram investigações sobre tal tema, (POSSAN et al. [8], GASPERIN [3], NASCIMENTO et al. [9]). SILVA [10] cita que esta manifestação patológica está diretamente ligada às condições da base. Pode ocorrer pela porosidade no substrato ser muito baixa, o que prejudica a absorção da pasta de cimento nos poros, responsáveis pela micro aderência. Também podem ocorrer pela superfície da base não apresentar rugosidade superficial, o que prejudica a macro aderência.

Ainda, com a necessidade de reduzir custos e a pressa em terminar as obras, algumas construtoras acabam pecando na execução dos serviços, utilizando muitas vezes mão-de-obra desqualificada. Acrescentase também que muitas vezes os prazos de cura não são respeitados e a execução dos serviços não seguem os prazos adequados. A má execução de um serviço gera um retrabalho, o que diretamente gera um custo adicional que não estava previsto inicialmente. A escolha do chapisco adequado, junto da sua correta execução $\mathrm{e}$ da preparação pertinente do substrato devem garantir uma aderência adequada, evitando a ocorrência destas manifestações patológicas. Além disso, segundo VIEIRA et al.[11], deve-se levar em consideração as condições ambientais, principalmente associadas com as elevadas variações térmicas em curtos períodos de tempo presentes em muitas capitais, prejudicando o desempenho desejado dos revestimentos.

KAZMIERCZAK et al [12] reforçam a ideia de que a diminuição excessiva nos prazos das construções, assim como as condições em que os revestimentos de argamassas ficam expostos, contribuem para a ocorrência de problemas de aderência. Portanto, podem ser desencadeados pela técnica executiva ou pela característica das argamassas, o que justifica a realização de estudos científicos relacionados ao tema.

Em função dos aspectos apresentados, o presente trabalho tem como objetivo principal estudar a influência da resistência do concreto na resistência de aderência à tração de chapiscos. Como objetivos específicos podem ser citados: (i) definir o chapisco que melhor se comporta frente ao aumento de resistência do concreto; (ii) comprovar a diminuição da resistência de aderência de revestimentos de argamassa sobre substratos de concreto mais resistentes; (iii) verificar, para todas as resistências do substrato, se todos tipos de chapisco atendem o requisito mínimo determinado na norma brasileira.

Foram testados diferentes tipos de chapisco (convencional, rolado e desempenado) a fim de buscar aquele que garanta melhor resistência à tração em relação ao aumento da resistência do concreto do substrato. Este trabalho delimita-se ao uso do concreto como único substrato estudado, com diferentes traços para atingir diferentes resistências à compressão. Como o estudo dar-se-á apenas sobre o chapisco, o revestimento (reboco) não será executado, a fim de eliminar variáveis que poderiam interferir nos resultados. 


\section{MATERIAIS E MÉTODOS}

\subsection{Materiais empregados para confecção dos substratos}

Foi empregado o cimento Portland pozolânico CP IV 32, cujas características físicas e químicas encontramse apresentadas nas Tabelas 1 e 2, respectivamente.

Tabela 1: Caracterização física do cimento CP IV 32

\begin{tabular}{|c|c|c|}
\hline \multicolumn{2}{|l|}{ ENSAIO } & RESULTADO \\
\hline \multicolumn{2}{|l|}{ Resíduo \# 0,075 mm } & $0,6 \%$ \\
\hline \multicolumn{2}{|l|}{ Resíduo \# 0,045 mm } & $5,4 \%$ \\
\hline \multicolumn{2}{|l|}{ Teor de carbono } & $4,95 \%$ \\
\hline \multicolumn{2}{|l|}{ Peso específico } & $2,74 \mathrm{~g} / \mathrm{cm}^{3}$ \\
\hline \multicolumn{2}{|l|}{ Superfície específica } & $1,23 \mathrm{~m}^{2} / \mathrm{g}$ \\
\hline \multirow{3}{*}{ Resistência mecânica (MPa) } & 3 dias & 16,8 \\
\hline & 7 dias & 23,5 \\
\hline & 28 dias & 38,7 \\
\hline
\end{tabular}

Tabela 2: Caracterização química do cimento CP IV 32

\begin{tabular}{l|c}
\hline \multicolumn{1}{|c|}{ COMPOSTO } & VALOR (\%) \\
\hline $\mathrm{SiO}_{2}$ & 31,7 \\
\hline $\mathrm{Al}_{2} \mathrm{O}_{3}$ & 10,01 \\
\hline $\mathrm{Fe}_{2} \mathrm{O}_{3}$ & 3,04 \\
\hline $\mathrm{CaO}$ & 45,07 \\
\hline $\mathrm{MgO}$ & 5,98 \\
\hline $\mathrm{SO}_{3}$ & 2,76 \\
\hline $\mathrm{Na}_{2} \mathrm{O}$ & 0,17 \\
\hline $\mathrm{K}_{2} \mathrm{O}$ & 0,96 \\
\hline $\mathrm{Cal}$ livre & 1,67 \\
\hline Perda ao fogo & 4,02 \\
\hline Resíduo insolúvel & 32,14 \\
\hline
\end{tabular}

A areia utilizada no concreto para confecção dos substratos foi a areia comercialmente chamada de areia quartzosa média, extraída do rio Jacuí, cujas características encontram-se apresentadas na Tabela 3.

Tabela 3: Caracterização do agregado miúdo empregado

\begin{tabular}{|c|c|c|c|}
\hline $\begin{array}{c}\text { DETERMINA- } \\
\text { ÇÕES }\end{array}$ & $\begin{array}{c}\text { MÉTODO DE EN- } \\
\text { SAIO }\end{array}$ & RESULTADOS & 3TIDOS \\
\hline \multirow{7}{*}{$\begin{array}{l}\text { Composição } \\
\text { Granulométrica }\end{array}$} & \multirow{7}{*}{ NBR NM 248 [13] } & $\begin{array}{c}\text { Abertura da peneira } \\
\text { ABNT (mm) }\end{array}$ & $\begin{array}{c}\text { Percentagem } \\
\text { acumulada }\end{array}$ \\
\hline & & 2,36 & 3 \\
\hline & & 1,18 & 10 \\
\hline & & 0,6 & 32 \\
\hline & & 0,3 & 84 \\
\hline & & 0,15 & 99 \\
\hline & & $<0,15$ & 100 \\
\hline \multicolumn{3}{|c|}{ Dimensão máxima característica (mm) } & 2,36 \\
\hline
\end{tabular}




\begin{tabular}{c|c}
\hline Módulo de finura & 2,28 \\
\hline Massa específica $\left(\mathrm{kg} / \mathrm{cm}^{3}\right)$ & 2,65 \\
\hline Massa unitária $\left(\mathrm{kg} / \mathrm{cm}^{3}\right)$ & 1,50 \\
\hline
\end{tabular}

Como agregado graúdo foi empregada a pedra britada de origem basáltica, cujas características encontram-se apresentadas na Tabela 4.

Tabela 4: Caracterização do agregado graúdo empregado

\begin{tabular}{|c|c|c|c|}
\hline DETERMINAÇÕES & $\begin{array}{c}\text { MÉTODO DE } \\
\text { ENSAIO }\end{array}$ & \multicolumn{2}{|c|}{ RESULTADOS OBTIDOS } \\
\hline \multirow{8}{*}{$\begin{array}{l}\text { Composição Granu- } \\
\text { lométrica }\end{array}$} & \multirow{8}{*}{$\begin{array}{c}\text { NBR NM } 248 \\
{[13]}\end{array}$} & $\begin{array}{c}\text { Abertura da peneira } \\
\text { ABNT (mm) }\end{array}$ & $\begin{array}{c}\text { Percentagem } \\
\text { acumulada }\end{array}$ \\
\hline & & 19 & 1 \\
\hline & & 12,5 & 52 \\
\hline & & 9,5 & 75 \\
\hline & & 6,3 & 97 \\
\hline & & 4,75 & 99 \\
\hline & & 2,36 & 100 \\
\hline & & $<2,36$ & 100 \\
\hline \multicolumn{3}{|c|}{ Dimensão máxima característica (mm) } & 19 \\
\hline \multicolumn{3}{|c|}{ Módulo de finura } & 6,75 \\
\hline \multicolumn{3}{|c|}{ Massa específica $\left(\mathrm{kg} / \mathrm{dm}^{3}\right)$} & 2,85 \\
\hline \multicolumn{3}{|c|}{ Massa unitária $\left(\mathrm{kg} / \mathrm{dm}^{3}\right)$} & 1,39 \\
\hline
\end{tabular}

Fornecida pelo abastecimento local, a água utilizada foi a proveniente da rede pública, tratada e distribuída pelo DMAE (Departamento de Água e Esgoto de Porto Alegre). Para a confecção das fôrmas, foi utilizado compensado plastificado.

\subsection{Materiais empregados para a confecção dos chapiscos}

A areia utilizada no chapisco convencional foi a mesma areia empregada para a confecção dos concretos (Tabela 3). Também utilizou-se o cimento CP IV-32 como aglomerante, cujas características são as mesmas dos concretos de substrato. Assim como para confecção dos substratos, a água utilizada foi a proveniente da rede pública, tratada e distribuída pelo DMAE.

Tanto o chapisco desempenado utilizado (também chamado de chapisco colante ou adesivo), quanto o chapisco rolado utilizado, foram adquiridos industrializados, apenas necessitando o acréscimo de água à mistura. As características desses materiais, segundo o fabricante, estão apresentadas na Tabela 5.

Tabela 5: Caracterização dos chapiscos industrializados empregados

\begin{tabular}{l|l|l|l|l|l}
\hline $\begin{array}{l}\text { TIPO DE CHA- } \\
\text { PISCO }\end{array}$ & $\begin{array}{l}\text { DENSIDADE } \\
\text { APARENTE }\end{array}$ & $\begin{array}{l}\text { DENSIDADE } \\
\text { FRESCA }\end{array}$ & $\begin{array}{l}\text { TEMPO EM } \\
\text { ABERTO }\end{array}$ & ADERÉNCIA & CONSUMO \\
\hline Desempenado & $1,7 \mathrm{~g} / \mathrm{cm}^{3}$ & $1,9 \mathrm{~g} / \mathrm{cm}^{3}$ & - & $\begin{array}{l}>0,5 \mathrm{MPa} \text { aos } \\
28 \mathrm{dias}\end{array}$ & $4,20 \mathrm{~kg} / \mathrm{m}^{2}$ \\
\hline Rolado & $1,6 \mathrm{~g} / \mathrm{cm}^{3}$ & $1,9 \mathrm{~g} / \mathrm{cm}^{3}$ & $2 \mathrm{~h} \mathrm{a} 20^{\circ} \mathrm{C}$ & $\begin{array}{l}>0,5 \mathrm{MPa} \text { aos } \\
28 \mathrm{dias}\end{array}$ & $\begin{array}{l}\text { Substrato de con- } \\
\text { creto } 1,2 \mathrm{~kg} / \mathrm{m}^{2}\end{array}$ \\
\hline
\end{tabular}




\subsection{Método}

\subsubsection{Moldagem dos substratos de concreto}

Para moldagem dos substratos com diferentes resistências, foram utilizados três diferentes traços. Para todos, foi considerado um teor de argamassa igual a 53\%, cujos traços estão apresentados na Tabela 6.

Tabela 6: Traços para substratos de concreto

\begin{tabular}{|c|c|c|c|c|c|c|}
\hline $\begin{array}{l}\text { RESISTÊNCIA } \\
\text { ESTIMADA (28 } \\
\text { DIAS) }\end{array}$ & RELAÇÃO a/c & m & \multicolumn{2}{|c|}{$\begin{array}{l}\text { TRAÇO EM } \\
\text { MASSA }\end{array}$} & $\begin{array}{l}\text { CONSUMO } \\
\left(\mathrm{kg} / \mathrm{m}^{3}\right)\end{array}$ & $\begin{array}{l}\text { ABATIMENTO } \\
(\mathrm{mm})\end{array}$ \\
\hline \multirow{4}{*}{20} & \multirow{4}{*}{0,61} & \multirow{4}{*}{6,60} & Cimento & 1,00 & 287,60 & \multirow{4}{*}{80} \\
\hline & & & Areia & 3,03 & 870,44 & \\
\hline & & & Brita & 3,57 & 1026,94 & \\
\hline & & & Água & 0,61 & 175,44 & \\
\hline \multirow{4}{*}{30} & \multirow{4}{*}{0,48} & \multirow{4}{*}{4,48} & Cimento & 1,00 & 393,40 & \multirow{4}{*}{80} \\
\hline & & & Areia & 1,90 & 747,46 & \\
\hline & & & Brita & 2,58 & 1014,30 & \\
\hline & & & Água & 0,48 & 188,83 & \\
\hline \multirow{4}{*}{40} & \multirow{4}{*}{0,39} & \multirow{4}{*}{3,01} & Cimento & 1,00 & 527,90 & \multirow{4}{*}{80} \\
\hline & & & Areia & 1,13 & 596,53 & \\
\hline & & & Brita & 1,88 & 993,14 & \\
\hline & & & Água & 0,39 & 205,88 & \\
\hline
\end{tabular}

Para simular condições reais de aplicação foram moldadas seis placas, duas para cada resistência estabelecida (20, 30 e $40 \mathrm{MPa})$, utilizando fôrmas com dimensões de 50 x 60 x $5 \mathrm{~cm}$, feitas de compensado plastificado. Foi escolhido este tipo de compensado pois o mesmo apresenta baixa porosidade, o que garante uma superfície extremamente lisa. Todas as placas foram adensadas com a utilização de um vibrador mecânico. Vale salientar que não foi utilizado nenhum tipo de desmoldante, visto que as chapas de compensado usadas nas formas eram novas e visando eliminar qualquer fator que pudesse exercer influência nos resultados. Os resultados do ensaio de resistência à compressão dos corpos de prova moldados estão apresentados na Tabela 7.

Tabela 7: Resistências dos concretos empregados nos substratos

\begin{tabular}{l|l}
\hline $\mathbf{f}_{\mathrm{c} 28}$ ESPERADO (MPa) & $\mathbf{f}_{\mathrm{c} 28}$ OBTIDO (MPa) \\
\hline 20 & 17,75 \\
\hline 30 & 29,87 \\
\hline 40 & 35,15 \\
\hline
\end{tabular}

\subsubsection{Revestimento dos substratos com diferentes tipos de chapiscos}

Passados 28 dias após a moldagem dos substratos, as placas de concreto foram chapiscadas. Para simular a superfície de vigas, pilares e lajes, o lado em que foi aplicado o revestimento foi o que ficou em contato com o fundo da fôrma. Antes da aplicação do revestimento o substrato escovado e posteriormente umedecido, conforme mostrado na Figura 1, para evitar que o mesmo absorvesse a água de hidratação do chapisco imediatamente após o seu lançamento. Todos tipos de substrato receberam os três tipos de revestimento. 


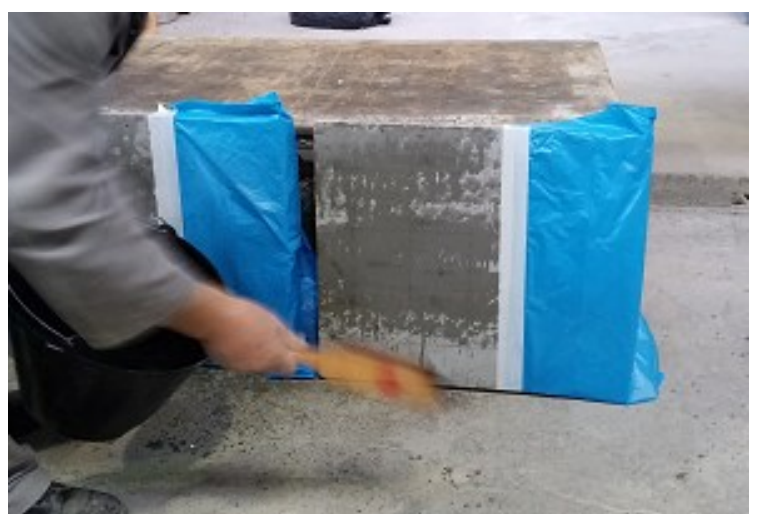

Figura 1: Umedecimento do substrato

Logo após o umedecimento, as placas foram chapiscadas com o chapisco convencional, rolado e desempenado, conforme mostrado na Figura 2.
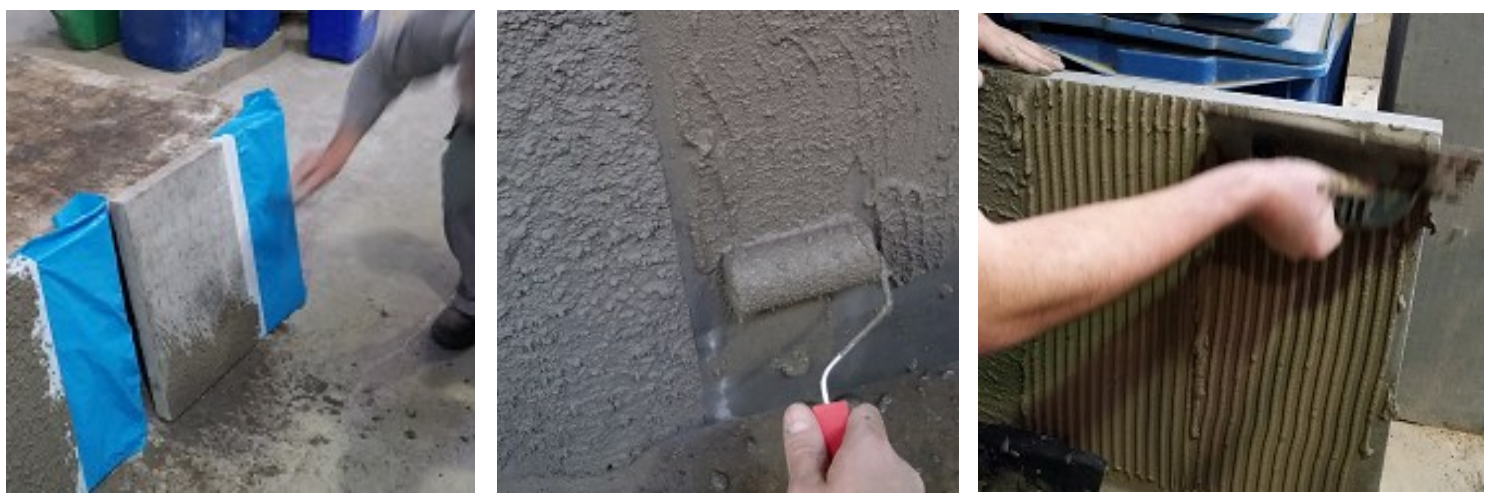

Figura 2: Execução do chapisco convencional, rolado e desempenado, respectivamente

O chapisco convencional foi executado com traço na proporção 1:3 em massa, ou seja, uma porção de cimento para três de agregado miúdo, em volume. Tal proporcionamento já foi empregado em trabalhos anteriores (RUDUIT [6] e GASPERIN [3]), cuja quantidade de água foi realizada com o auxílio de um profissional experiente na aplicação do chapisco. A água foi acrescida na mistura até que o profissional, após aplicações experimentais sucessivas, informasse que o material apresentava uma consistência adequada para o uso. A aplicação foi feita com a projeção da argamassa de chapisco através de uma colher de pedreiro.

Para a execução do chapisco rolado foi utilizada a argamassa industrializada, havendo apenas a necessidade de misturar a quantidade de água determinada previamente pelo fabricante. A aplicação foi feita através de um rolo de espuma, específico para texturas.

Para a execução do chapisco desempenado também foi utilizada a argamassa industrializada. Foi adicionada a quantidade de água indicada pelo fabricante para atingir o proporcionamento correto. A aplicação foi feita com o uso de uma desempenadeira dentada de aço. Primeiramente foi aplicada a argamassa com o lado liso da desempenadeira e posteriormente passado o lado dentado para a criação dos cordões.

\subsubsection{Ensaios de resistência de aderência à tração}

Os ensaios de aderência foram feitos conforme as orientações da NBR 13528 [14]. Foram executadas 6 amostras para cada combinação chapisco/substrato. Após a marcação dos centros das amostras, foi usada uma serra copo acoplada a uma furadeira para delimitar a área de cada extração. Foi respeitado o espaçamento de $50 \mathrm{~mm}$, entre amostras e afastado das bordas, indicado pela norma. Após a demarcação, foi removido da superfície o excesso de pó gerado pelo corte das amostras e as pastilhas foram coladas diretamente sobre o chapisco, conforme mostrado na Figura 3, com a utilização de adesivo epóxi. 


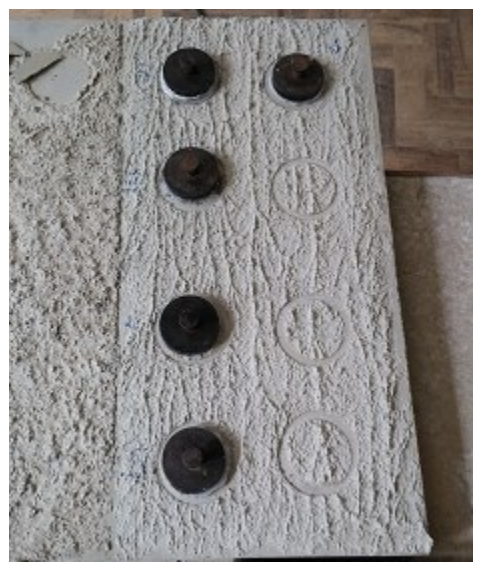

Figura 3: Pastilhas para ensaio de aderência

Posteriormente à cura do adesivo, foram executadas as extrações com a utilização de um dinamômetro de tração. Na Figura 4 podem ser observados dois exemplos de ruptura: uma na interface chapisco/substrato e outra no rompimento da argamassa de chapisco. Destaca-se que, para um total de 54 amostras, ocorreram 48 rompimentos na interface chapisco/substrato e 6 rompimentos no revestimento.
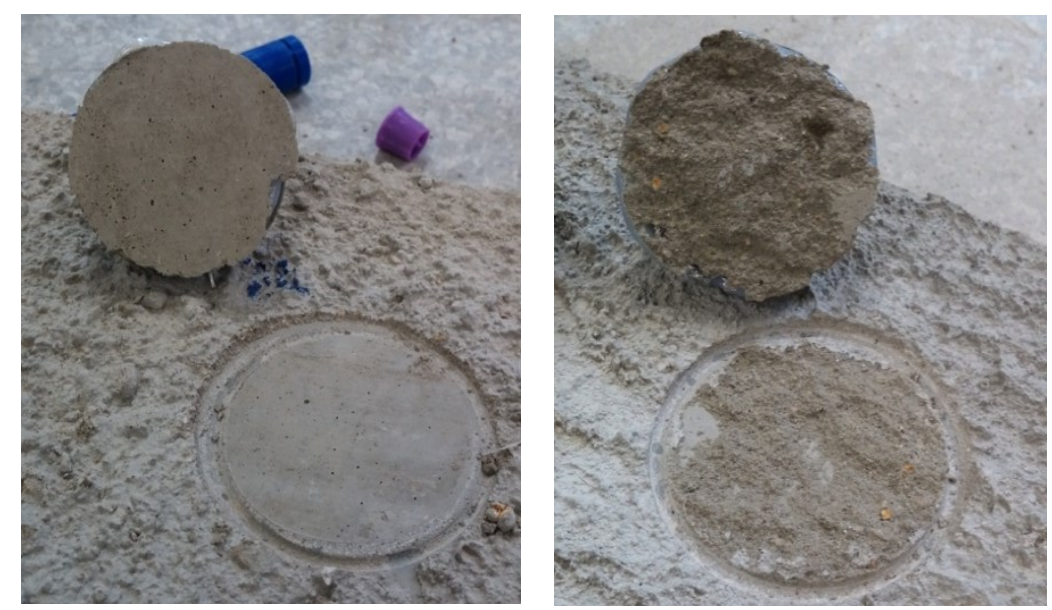

Figura 4: Pastilhas após extração. Rompimento na interface chapisco/substrato (esq.) e rompimento na argamassa de chapisco (dir.)

\subsubsection{Porosidade, absorção d'água por imersão e massa específica}

Para verificar a porosidade e a absorção d'água do concreto utilizado na confecção dos substratos, foi feito ensaio de absorção para cada traço. Os exemplares foram imersos em um tanque com água onde ficaram por 25 dias, desde a desmoldagem, que ocorreu 3 dias após a moldagem, até a data do ensaio, aos 28 dias. Após a retirada de dentro do tanque, foram pesados para determinação da massa no estado saturado. Após a verificação, foram colocados em uma estufa para secagem, à $100^{\circ} \mathrm{C}$. Quando atingiram a constância de massa, foram retirados da estufa e novamente pesados para a determinação da massa no estado seco. Com os valores obtidos, foi possível calcular o percentual de absorção d'água, porosidade aparente e massa específica.

\section{RESULTADOS}

$\mathrm{Na}$ sequência serão apresentados e discutidos os resultados obtidos, considerando tanto o tipo de chapisco quanto a resistência do substrato de concreto. Foram calculados os valores médios e os desvios-padrão para cada ensaio, como apresentado nos itens a seguir. 


\subsection{Efeito do tipo de chapisco}

A Figura 5 compara as resistências obtidas quando ensaiado os chapiscos sobre substrato de 17,75 $\mathrm{MPa}$.

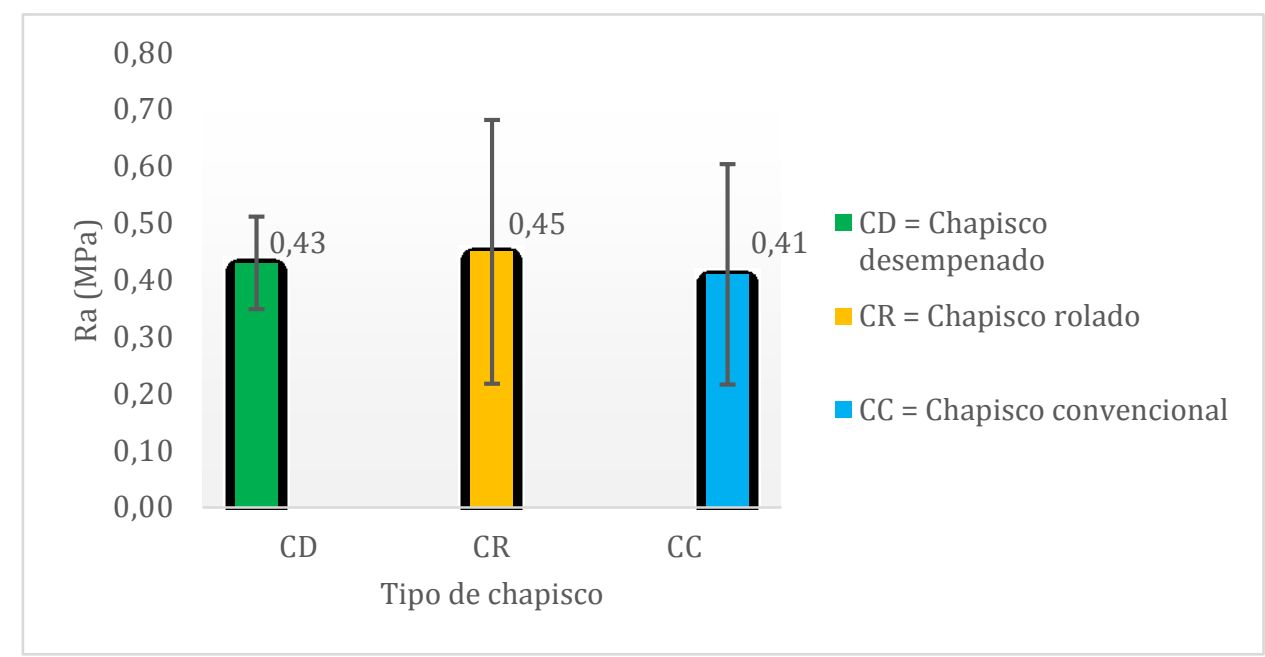

Figura 5: Resultados de Ra para o substrato de 17,75 Mpa

Pode-se observar que para este substrato com menor resistência, a variação entre as resistências médias é praticamente nula, apesar da grande variação entre os desvios padrão. Todos os chapiscos apresentaram resistência média superior ao mínimo requerido pela norma (0,20 MPa) (NBR 13281 [15]). $\mathrm{MPa}$

A Figura 6 compara as resistências obtidas quando ensaiados os chapiscos sobre substrato de 29,87

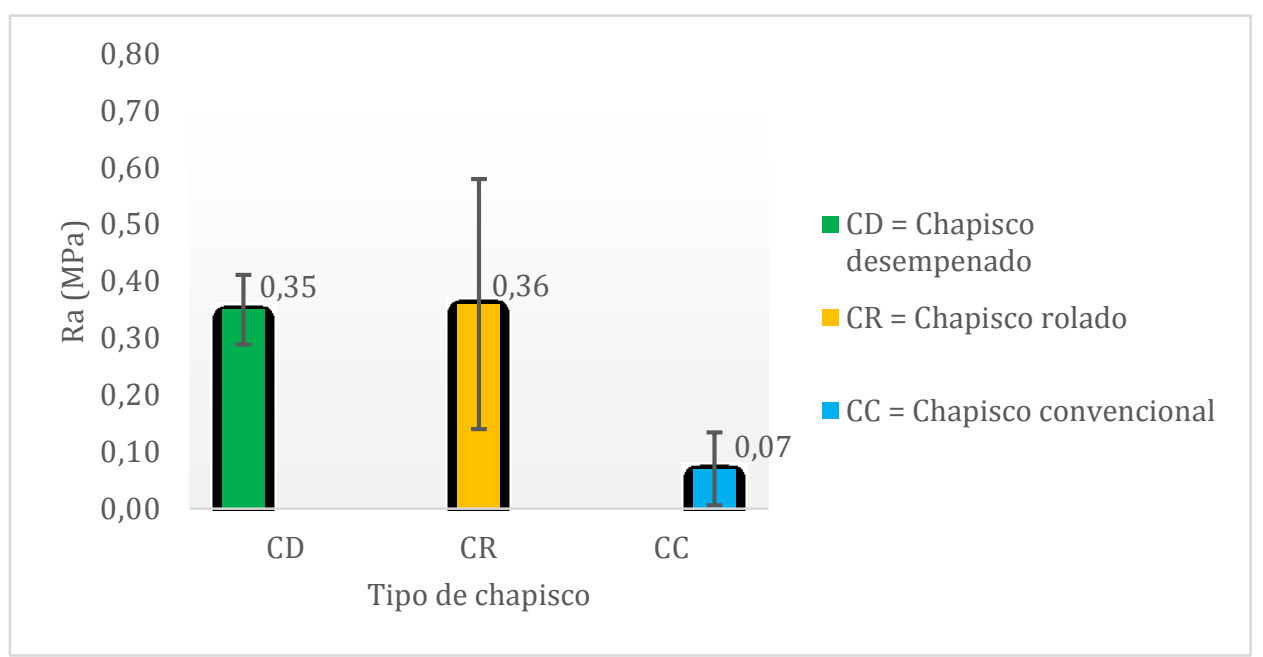

Figura 6: Resultados de Ra para o substrato de $29,87 \mathrm{MPa}$

Pode-se observar que para este substrato com resistência intermediária, houve grande variação de resistência média entre os chapiscos industrializados e o chapisco convencional. Para este caso, os chapiscos desempenado e rolado atingiram resistências médias muito superiores ao convencional, sendo a deste último praticamente nula. Salienta-se também que as resistências médias atingidas por estes dois chapiscos industrializaram foram superiores ao mínimo exigido pela norma $(0,20 \mathrm{MPa})$. $\mathrm{MPa}$.

A Figura 7 compara as resistências obtidas quando ensaiados os chapiscos sobre substrato de 35,15 


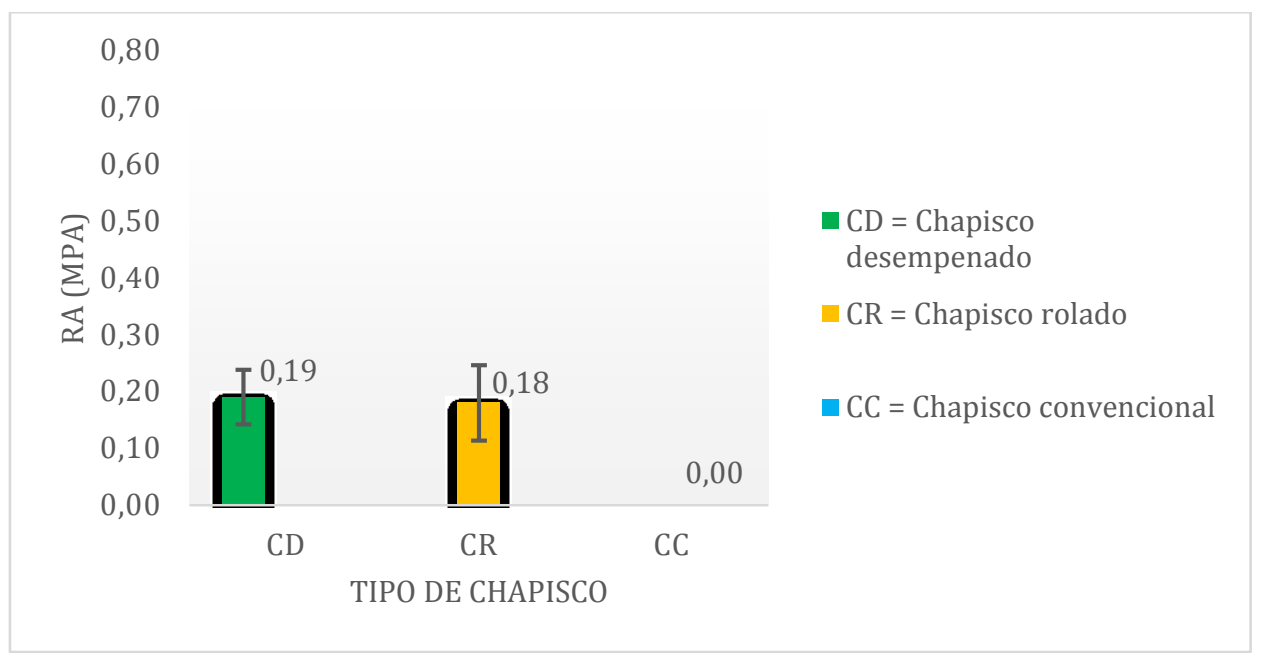

Figura 7: Resultados de Ra para o substrato de $35,15 \mathrm{MPa}$

Observa-se que, para este substrato de elevada resistência houve grande variação de resistência de aderência à tração entre os chapiscos industrializados e o chapisco convencional. Para este caso, os chapiscos desempenado e rolado também atingiram resistências muito superiores ao convencional, apesar de não atingirem o mínimo exigido pela norma (NBR 13749 [15]). Para o chapisco convencional não foi possível realizar o ensaio, pois o mesmo descolava do substrato no momento da delimitação da área de ensaio com a serra copo, verificando-se a ausência de aderência.

\subsection{Influência do substrato de concreto na resistência de aderência}

A Figura 8 compara as resistências obtidas quando ensaiado o chapisco desempenado sobre os substratos de concreto com diferentes resistências.

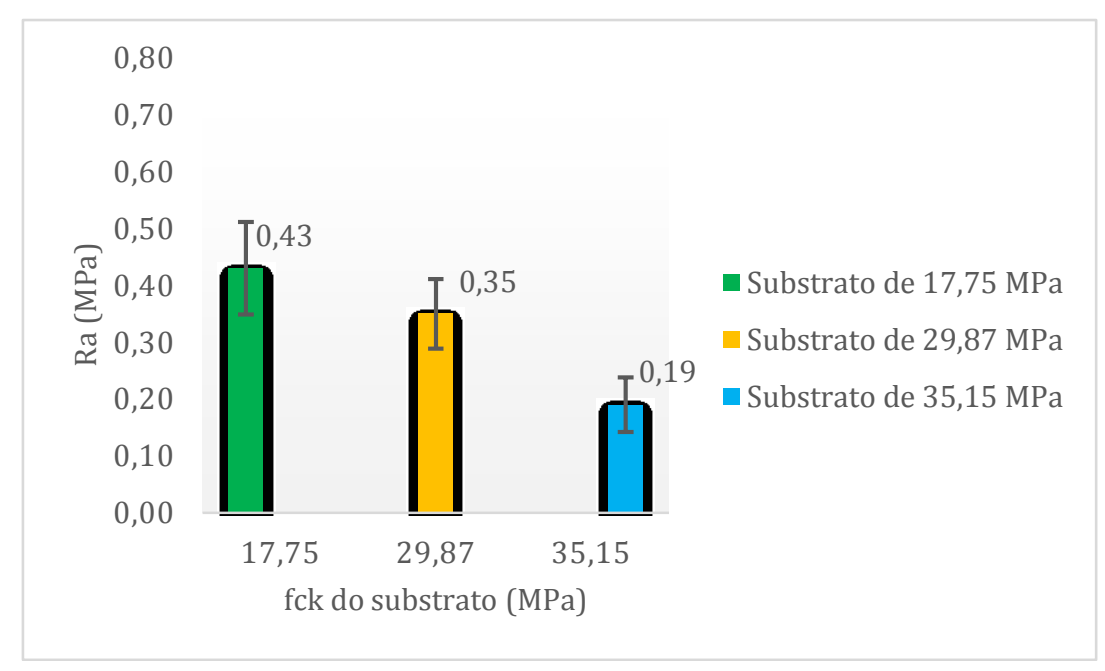

Figura 8: Desempenho do chapisco desempenado sobre substratos de concreto com diferentes resistências

Pode-se observar a diminuição da resistência média de aderência do chapisco à medida que aumenta a resistência do substrato. Este chapisco apresentou resistência média à tração superior ao exigido pela norma quando executado sobre os substratos de 17,75 e 29,87 MPa, porém inferior quando executado sobre o substrato de 35,15 MPa.

A Figura 9 compara os resultados obtidos quando ensaiado o chapisco rolado sobre os substratos de concreto com diferentes resistências. 


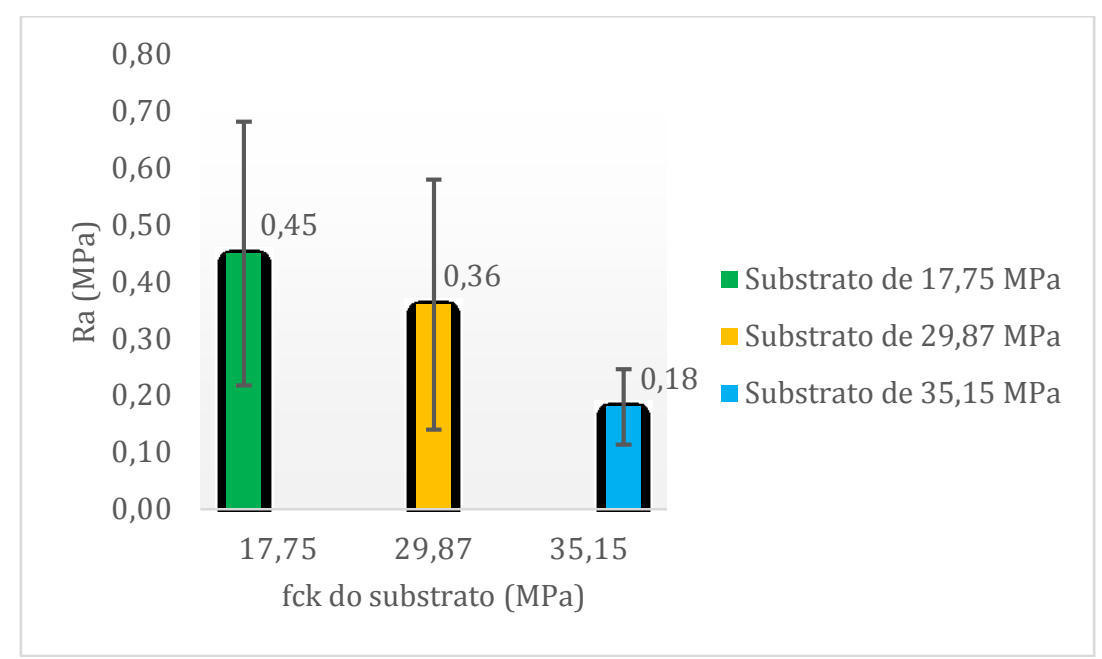

Figura 9: Desempenho do chapisco rolado sobre substratos de concreto com diferentes resistências

Também se observa a diminuição da resistência de aderência do chapisco à medida que aumenta a resistência do substrato. Assim como para o chapisco desempenado, este chapisco apresentou resistência à tração superior ao exigido pela norma quando executado sobre os substratos de 17,75 e 29,87 MPa, porém inferior quando executado sobre o substrato de $35,15 \mathrm{MPa}$. É possível observar também que houve um grande desvio padrão para as amostras deste tipo de chapisco, onde houveram amostras com resistências muito maiores e amostras com resistências muito menores comparadas à média.

A Figura 10 compara as resistências obtidas quando ensaiado o chapisco convencional sobre os substratos de concreto com diferentes resistências.

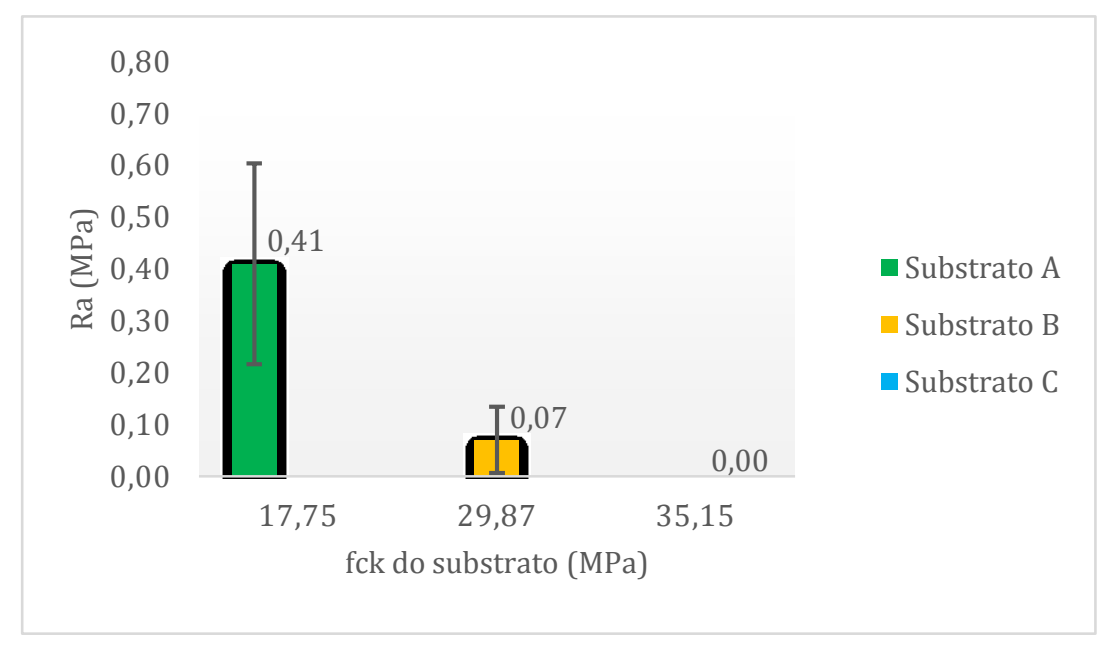

Figura 10: Desempenho do chapisco convencional sobre substratos de concreto com diferentes resistências

Pode-se observar a diminuição da resistência de aderência do chapisco à medida que aumenta a resistência do substrato. Diferentemente do que ocorreu com os chapiscos desempenado e rolado, este chapisco apresentou resistência média à tração superior ao exigido pela norma apenas quando executado sobre o substrato de 17,75 $\mathrm{MPa}$, sendo quase nulo quando executado sobre o substrato de 29,87 $\mathrm{MPa}$, e inviável quando executado sobre o substrato de $35,15 \mathrm{MPa}$.

\section{DISCUSSÃO}

Com base nos resultados obtidos foi realizada uma análise de variância (ANOVA), a fim de verificar se a resistência do concreto de substrato e o tipo de chapisco influenciam significativamente na resistência de aderência à tração. Os resultados da análise estão apresentados na Tabela 8. Vale salientar que um valor de ' $p$ ' menor que 0,05 indica que a relação entre as variáveis é estatisticamente significativa com um nível de confi- 
Tabela 8: ANOVA para a resistência de aderência à tração $\left(\mathrm{R}_{\mathrm{a}}\right)$

\begin{tabular}{l|l|l|l|l|l}
\hline $\begin{array}{l}\text { FONTE DE VARIA- } \\
\text { ÇÃO }\end{array}$ & GDL & SQ & MQ & TESTE F & $\begin{array}{l}\text { SIGNIFICÂNCIA } \\
-\mathbf{p}\end{array}$ \\
\hline Resistência do substrato & 2 & 0,8254 & 0,4127 & 23,093 & 0,0000 \\
\hline Tipo de chapisco & 2 & 0,3343 & 0,1672 & 9,355 & 0,0004 \\
\hline $\begin{array}{l}\text { Resistência do substrato } \\
* \text { Tipo de chapisco }\end{array}$ & 4 & 0,1292 & 0,0323 & 1,808 & 0,1439 \\
\hline Erro & 45 & 0,8042 & 0,0179 & & \\
\hline
\end{tabular}

Onde: $\mathrm{GDL}=$ graus de liberdade; $\mathrm{SQ}=$ soma quadrada; $\mathrm{MQ}=$ média quadrada

Tem-se que os parâmetros principais (resistência do substrato de concreto e o tipo de chapisco) exercem influência na propriedade analisada. Além disso, levando-se em consideração os valores do teste F, verifica-se que a influência da resistência do concreto de substrato é muito mais significativa que o tipo de chapisco. Isso quer dizer que é muito mais importante considerar a resistência do concreto como um fator definidor na resistência de aderência à tração, independentemente do tipo de chapisco que será empregado. Resultados similares foram encontrados por MÜLLER [16], cujos chapiscos industrializados apresentaram diferenças estatísticas significativas se comparados ao chapisco convencional. Tal fato pode ser explicado em parte pelo teor de agregado miúdo (areia) na confecção do chapisco convencional, pois à medida que se aumenta a quantidade de areia há uma minimização da resistência de aderência, devido ao ar aprisionado durante o processo de mistura, que tende a minimizar a extensão de argamassa aderida no substrato de concreto.

Sendo assim, é possível comprovar a diminuição da resistência de aderência entre substrato e chapisco, à medida em que a resistência do substrato aumenta. Esta diminuição da resistência de aderência pode estar ligada à micro ancoragem, pois com o aumento da resistência do concreto ocorre a diminuição da sua porosidade, que confirma o que já havia sido relatado por outros autores como SCARTEZINI et al [17] e DUALIBE, CAVANI E OLIVEIRA [18]. Esta afirmação foi confirmada através dos resultados de caracterização dos substratos de concreto, conforme apresentado na Tabela 9.

Tabela 9: Características dos substratos de concreto

\begin{tabular}{l|l|l|l}
\hline $\mathbf{f}_{\mathbf{c}}(\mathbf{M P a})$ & ABSORÇÃO (\%) & POROSIDADE (\%) & MASSA ESPECÍFICA (kg/dm $\left.{ }^{\mathbf{3}}\right)$ \\
\hline 17,75 & 5,92 & 13,45 & 2,27 \\
\hline 29,87 & 4,78 & 11,06 & 2,32 \\
\hline 35,15 & 4,58 & 10,42 & 2,28 \\
\hline
\end{tabular}

A Figura 11 mostra a relação entre resistência de aderência, $f_{c}$ do substrato e absorção d'água. Fica evidenciado que, à medida que a resistência do concreto do substrato aumenta, a resistência de aderência e a absorção d'água diminuem. 


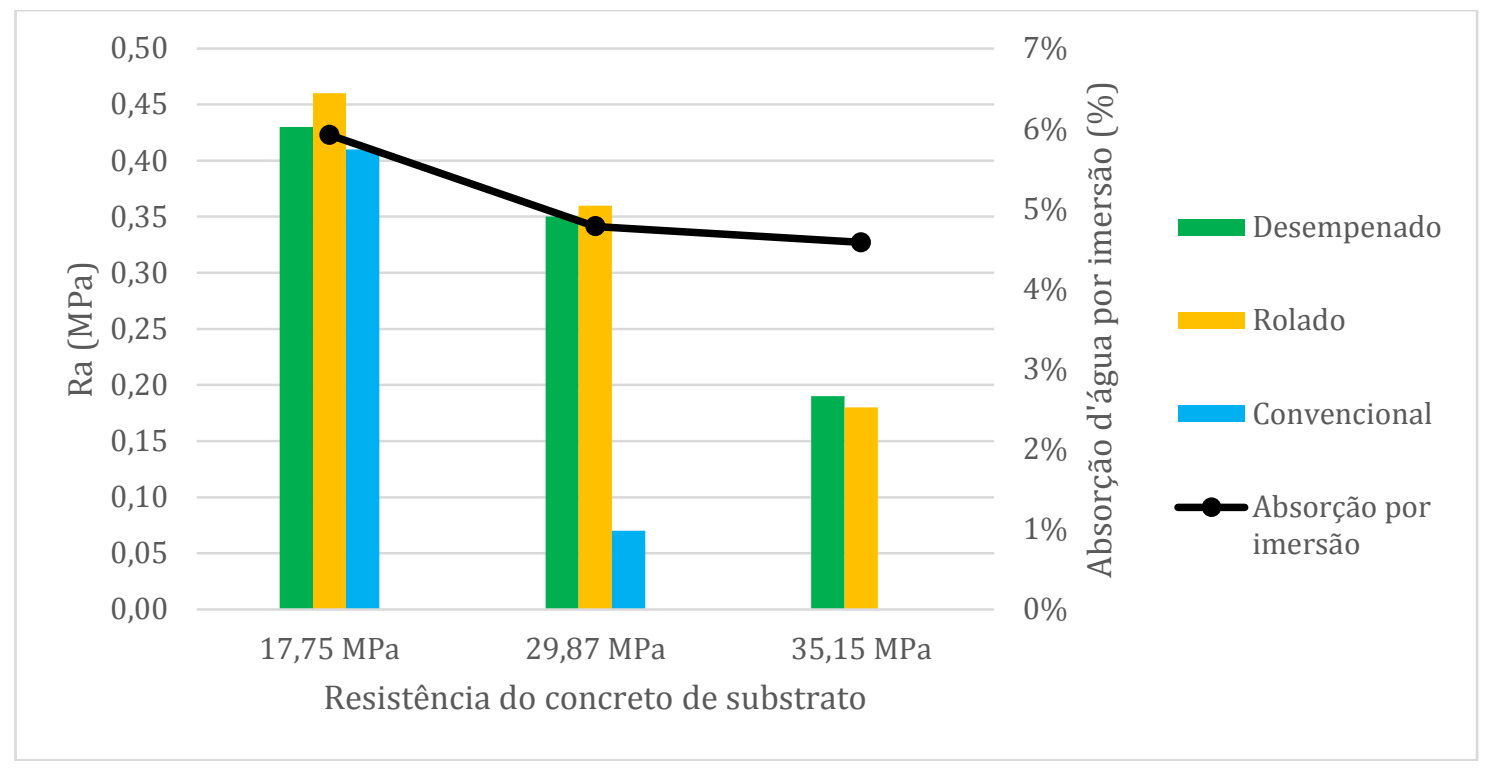

Figura 11: Relação entre resistência de aderência, $f_{c}$ do substrato e absorção d'água

Uma das explicações para a diminuição da resistência de aderência é justamente a diminuição da $a b-$ sorção d'água, devido à diminuição da porosidade aparente. Quando aumenta a porosidade, aumentam os poros onde a pasta com cimento penetra, promovendo ancoragem mecânica após a hidratação dos compostos. Quando aumenta a resistência do concreto e consequentemente ocorre a diminuição dos poros, ocorre uma diminuição do poder de ancoragem do revestimento. Tal tendência também foi observada no trabalho de PRETTO [7] ao investigar a aderência de diferentes tipos de chapisco com concretos com resistências iguais a $25 \mathrm{MPa}, 35 \mathrm{MPa}$ e $45 \mathrm{MPa}$. Conforme os resultados obtidos pelo autor, a influência da resistência do concreto tende a ser mais significativa quando comparam-se os resultados do concreto de maior resistência com os demais, comportamento este também observado na presente investigação (Figura 11). Além disso, ao estudar a influência de substratos de concreto com 30, 40 e $50 \mathrm{MPa}$, SILVA et al. [19] verificaram que existem diferenças significativas entre os substratos na aderência de diferentes tipos de argamassas industrializadas investigadas. Tal comportamento está diretamente relacionado com a distribuição de poros do substrato (diâmetro, estrutura e volume), aliada à interação com o tipo de revestimento, fatores que possuem influência significativa na resistência de aderência (PAES et al. [20]).

Os resultados dos ensaios de aderência podem ser comparados com os resultados obtidos por PRETTO [7] e MÜLLER [16], cujos autores também comprovaram que os chapiscos industrializados (rolado e desempenado), apresentaram resistência de aderência superior quando comparados ao chapisco convencional. A maior resistência de aderência apresentada por estes chapiscos industrializados está ligada à presença de aditivos na fórmula destes, visto que sua composição básica também é feita de cimento e areia, como no chapisco convencional.

\section{CONCLUSÕES}

Com base nos resultados obtidos, podem ser destacados os seguintes pontos:

- Verificou-se que, à medida que há um aumento da resistência do concreto de substrato, ocorre uma minimização da resistência de aderência do chapisco, independentemente do tipo. Isso é de grande importância no momento de se projetar uma estrutura, pois as especificações de revestimento devem estar alinhadas com os valores de resistência do substrato de concreto (que tentem a aumentar ao longo do tempo);

- Os chapiscos industrializados apresentam uma resistência de aderência maior que os chapiscos convencionais, para qualquer valor de resistência do concreto.

Tais considerações são extremamente importantes sob o ponto de vista tecnológico, pois apresenta um indicativo claro do tipo de material que deve ser empregado na execução de revestimentos nas construções. Esse aspecto merece especial atenção ao se considerar edifícios de múltiplos pavimentos com elevadas alturas, que normalmente são revestidos com argamassas ou placas cerâmicas. Caso a camada de chapisco não possua uma aderência satisfatória poderá ocorrer o desplacamento do revestimento, caracterizando-se como um perigo para os usuários dessas construções. 


\section{BIBLIOGRAFIA}

[1] CARASEK, H., “Argamassas”, In: Isaia G.C., (ed.). Materiais de Construção Civil e Princípios de Ciência e Engenharia de Materiais, São Paulo, IBRACON, pp. 892-944, 2010.

[2] CARASEK, H., CASCUDO O., JUCÁ T., "Estudo de casos de descolamento de revestimento de argamassa aplicado sobre estrutura de concreto", In: Anais do II Simpósio Brasileiro de Tecnologia das Argamassas, pp. 551-561, Salvador, 2005.

[3] GASPERIN, J. Aderência de revestimentos de argamassa em substrato de concreto: influência da forma de aplicação e composição do chapisco, Dissertação de M.Sc., Programa de Pós-Graduação em Engenharia Civil - UFRGS, Porto Alegre, RS, Brasil, 2011.

[4] MEHTA, P.K., MONTEIRO P.J.M., Concrete: Microstructure, Properties, and Materials. 3th ed, McGraw-Hill, Ney York, 2006.

[5] AÏTICIN, P.C., Concreto de alto desempenho. 1a Edição ed, São Paulo, PINI, 2000.

[6] RUDUIT, F.R. Contribuição ao estudo da aderência de revestimentos de argamassa e chapiscos em substrato de concreto, Dissertação de M.Sc., Programa de Pós-Graduação em Engenharia Civil - UFRGS, Porto Alegre, RS, Brasil, 2009.

[7] PRETTO, M.R.E.J. Influência da rugosidade gerada pelo tratamento superficial do substrato de concreto na aderência do revestimento de argamassa, Dissertação de M.Sc., Programa de Pós-Graduação em Engenharia Civil - UFRGS, Porto Alegre, RS, Brasil, 2007.

[8] POSSAN, E., GAVA G.P., PETRAUSKI S.C., "Estudo comparativo do desempenho de argamassas de revestimento produzidas em obra e industrializadas em diferentes substratos", In: Anais do IX Encontro Nacional de Tecnologia do Ambiente Construído, pp. 1241-1250, Foz do Iguaçu, 2002.

[9] NASCIMENTO, O.L., MANSUR A.A.P., RIBEIRO A.B., et al., "Estudo da influência de aditivo adesivo e de tipos de cimento na aderência de chapisco em base de concreto", In: Anais do VI Simpósio Brasileiro de Tecnologia das Argamassas, pp. 508-517, Florianópolis, 2005.

[10] SILVA, A.F. Manifestações patológicas em fachadas com revestimentos argamassados: estudo de caso em edifícios em Florianópolis, Dissertação de M.Sc., Programa de Pós-Graduação em Arquitetura e Urbanismo - UFSC, Florianópolis, SC, Brasil, 2007.

[11] VIEIRA, F.M.P., KAZMIERCZAK C.S., MASUERO A.B., et al., Influência dos tipos de substrato e argamassa na aderência dos revestimentos de argamassa, Comunidade da Construção, Porto Alegre, Associação Brasileira de Cimento Portland; 28p, 2005.

[12] KAZMIERCZAK, C.D.S., BREZEZINSKI D.B.E., COLLATTO D.C., "Influência das características da base na resistência de aderência à tração e na distribuição de poros de uma argamassa", Estudos Tecnológicos, v. 1, n. 3, pp. 47-58, 2007.

[13] ASSOCIAÇÃO BRASILEIRA DE NORMAS TÉCNICAS. NBR NM 248: Agregados - Determinação da composição granulométrica. Rio de Janeiro, 2003.

[14] NBR 13528: Revestimento de paredes e tetos de argamassas inorgânicas -

Determinação da resistência de aderência à tração. Rio de Janeiro, 2010.

[15] NBR 13281: Argamassa para assentamento de paredes e revestimento de paredes e tetos - Requisitos. Rio de Janeiro, 2005.

[16] MULLER, A.A. Avaliação da aderência dos diferentes tipos de chapisco sobre substrato de concreto, Trabalho de Graduação em Engenharia, UFRGS, Porto Alegre, RS, Brasil, 2010.

[17] SCARTEZINI, L.M., JUCÁ T.R., LINHARES H., et al., "A influência do preparo da base na aderência e na permeabilidade à àgua dos revestimentos de argamassa”, Ambiente Construído, v. 2, n. 2. pp.85-92, 2002.

[18] DUALIBE, R.P., CAVANI G.R., OLIVEIRA M.C.B., "Influência do tipo de projeção da argamassa na resistência de aderência à tração e permeabilidade à água", In: Anais do VI Simpósio Brasileiro de Tecnologia das Argamassas, pp. 508-517, Florianópolis, SC, Brasil, 2005.

[19] SILVA, V.S., GOMES A.D.O., MARQUES P.D.P., et al., "Aderência de chapiscos com aditivos à base de resina acrílica em concretos estruturais”, In: Anais do IX Simpósio Brasileiro de Tecnologia das Argamassas, 10p, Belo Horizonte, MG, Brasil, 2011.

[20] PAES, I.L., BAUER E., CARASEK H., "Influência da estrutura de poros de argamassas mistas e de blocos de concreto e cerâmico no desempenho dos revestimentos", In: Anais do VI Simpósio Brasileiro de Tecnologia das Argamassas, Florianópolis, SC, Brasil, 2005. 